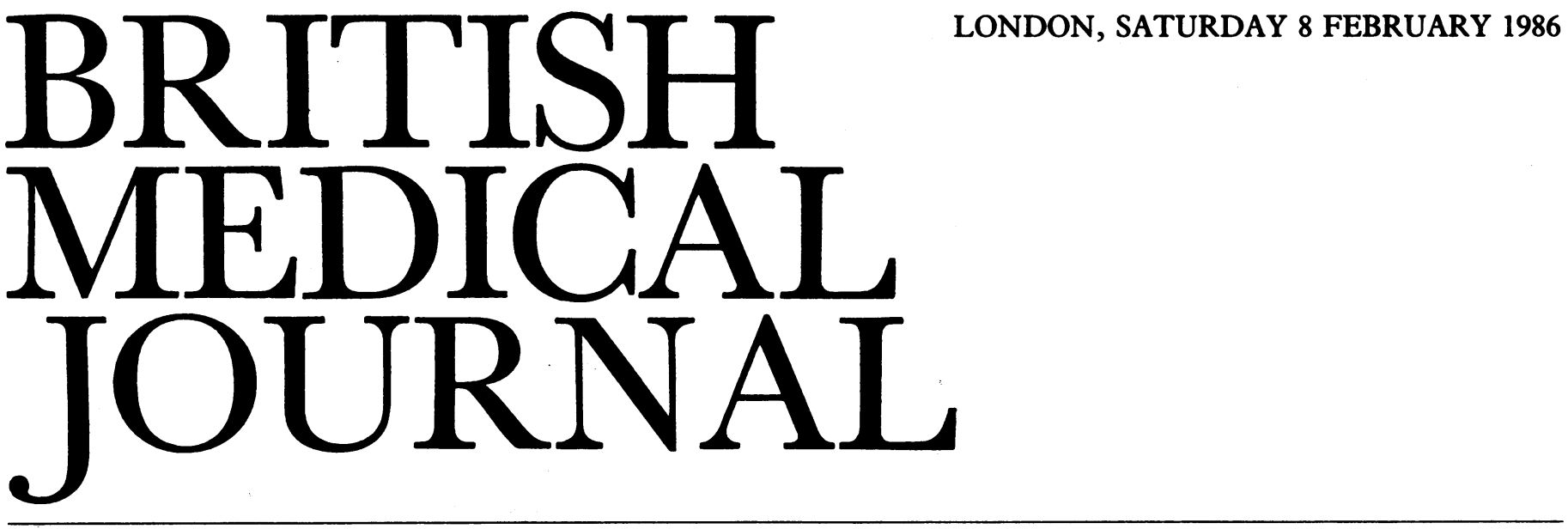

\title{
Narcolepsy and immunity
}

Twenty thousand people in Britain and 100000 in the United States believe they have narcolepsy-estimates derived from newspaper advertisements, television, and telephone surveys. ${ }^{1}$ Undoubtedly some of these do not have true narcolepsy (the specific syndrome of narcolepsy/cataplexy), but many cases go undiscovered, and the condition is common.

Narcolepsy is not a life threatening illness, but excessive daytime drowsiness, due to this or other causes, is a formidable health problem. Many sufferers from narcolepsy are bitter about their illness, and some complain that they spend most of their lives asleep. Narcolepsy causes difficulties throughout life: problems at work, broken marriages, and industrial and road traffic accidents. The recent foundation of the United Kingdom Narcolepsy Association (c/o Central Manchester Community Health Council, St Ann's Churchyard, Manchester M2 7LN) is a landmark in the history of this strange disorder.

The clinical features of narcolepsy are well described in two books published recently. ${ }^{23}$ The diagnosis should be apparent from the history alone, but the condition is often missed. The usual age of onset is late puberty, but narcolepsy may start at any age from 5 to 70 . Sometimes the symptoms are attributed to laziness, or the condition may be confused with other causes of daytime drowsiness, notably sleep apnoea. The characteristic atonia and paralysis of cataplexy may be unreported or accepted as normal. Two other features-frequent sleep paralysis and presleep dreams -may help to confirm clinical suspicions, but these are not always present. A gap of over $\mathbf{4 0}$ years has been recorded between the onset of daytime drowsiness and a first attack of cataplexy. ${ }^{4}$

Narcolepsy is a disorder of rapid eye movement sleep, not of body clocks. ${ }^{5}$ Rapid eye movement sleep occurs at unusual times, including at the onset of sleep, and the normal accompaniments of this sleep stage-dreaming and muscle atonia - occur separately and during wakefulness. Rapid eye movement activity is not, however, always present in narcoleptics at sleep onset and may occur at this time in other conditions-for example, after sleep deprivation and in depressive illness. ${ }^{6}$ Sleep studies, which are very expensive and not widely available in Britain, may not, therefore, always confirm the diagnosis. Recently neurones generating rapid eye movement sleep have been localised to the junction of the pons and mesencephalon, ${ }^{7}$ but in the single detailed necropsy reported on a patient with narcolepsy no definite abnormality was found here or elsewhere in the brain. ${ }^{8}$

Familial narcolepsy has been known for a century, but no one could have predicted the near $100 \%$ association between narcolepsy and the major histocompatibility complex class II gene product HLA-DR2 (or DQ1) recently reported in Japan, France, and in Welsh's laboratory at Guy's Hospital, London. ${ }^{9-11}$ This is the highest disease linkage with HLA types known, and in our experience only $1-2 \%$ of patients with typical narcolepsy do not have the DR2 haplotype. And even in those without the DR2 haplotype Southern blot analysis of restriction fragment length polymorphisms shows similarities with patients who are DR2 positive.

There is no association between HLA types and two other causes of daytime drowsiness, sleep apnoea and nocturnal myoclonus. Most patients with the clinical diagnosis of "idiopathic" hypersomnolence-persistent daytime drowsiness without cataplexy or sleep paralysis-have proved to be DR2 (or DQ1) positive ( $\mathrm{K}$ Welsh, unpublished data). These people probably have narcolepsy.

Though the DR2 (or DQ1) haplotype is associated with narcolepsy, it does not cause the disease; indeed, this haplotype occurs in the British white population at a prevalence of about one in five, while only about one person in 2500 has narcolepsy. A specific submolecular fraction or epitope of the whole DR2 (or DQ1) molecule is probably associated with narcolepsy. Identification of this epitope would permit more accurate confirmation of the diagnosis than can be achieved by polysomnography. Prenatal diagnosis of the condition by amniocentesis may be possible in the future-but at a recent meeting of the United Kingdom Narcolepsy Association in Manchester only three of 35 women with narcolepsy considered that the disorder was a valid reason for the termination of pregnancy.

Environmental as well as genetic factors are probably responsible for narcolepsy. One hypothesis, that narcolepsy is an immune related disease, is supported by the similarity between $D$ related antigens in man and immune associated antigens in mice as well as the known associations between HLA types and immune abnormalities. Three lines of evidence from our experience support this belief. Firstly, in $15 \%$ of narcoleptics the onset is sudden, sometimes after a 
febrile and possibly viral illness, suggesting that narcolepsy may be "caught." Furthermore, recovery from typical narcolepsy does occur, though it is rare. Secondly, narcolepsy is sometimes associated with (though probably not caused by) multiple sclerosis, and it has also been reported with other immune associated disorders. Thirdly, a quarter of all narcoleptics have minor abnormalities in the cerebrospinal fluid including lymphocytosis, an increase in the protein content, and, in one case, oligoclonal bands. This evidence justifies a search for immune factors in narcolepsy; but, as with type I diabetes, a long search may be needed and patients will probably need to be studied soon after the onset of symptoms. ${ }^{12} 13$

Trials of immunosuppression in human narcolepsy are not justified, though the results of this treatment in narcoleptic dogs will be awaited with great interest. ${ }^{14} \mathrm{We}$ have done one plasma exchange of 6 litres in a patient with narcolepsy and severe cataplexy resistant to clomipramine, but it had no effect on sleep latency, daytime drowsiness, or cataplexy. Treatment relies on amphetamine-like drugs for narcolepsy and clomipramine for cataplexy, but the response is variable and side effects are frequent.

There is an unexpected genetic as well as clinical association between narcolepsy and multiple sclerosis (A So, $\mathrm{J}$ Trowsdale, $\mathrm{K}$ Welsh, personal communication). Between $40 \%$ and $80 \%$ of patients with multiple sclerosis are DR2 positive. Almost all DR2 positive patients with multiple sclerosis appear to have the same $\mathrm{DQ} \beta$ molecular subtype as occurs in narcolepsy.

We are most grateful to our colleagues for help in preparing this report, in particular K Welsh, D Vergani, and N Dodd. Equipment for plasmapheresis was kindly supplied by Haemonetics.

J D PARKES

Reader in neurology

N LANGDON

Research registrar

Department of Neurology,

King's College Hospital, London SE5 9RS

C Lock

Department of Neurology,

Research registrar

King's College Hospital, London SE5 9RS; and

Tissue Typing Laboratory,

Guy's Hospital, London SE1 9RT

1 Dement WC. Daytime sleepiness and sleep "attacks." In: Guilleminault C, Dement WC Passouant P, eds. Narcolepsy. New York: Spectrum, 1976:17-42.

2 Guilleminault C, Dement WC, Passouant P, eds. Narcolepsy. New York: Spectrum, 1976: 1-689.

3 Roth B. Narcolepsy and hypersomnia. Basle: Karger, 1980:1-310.

4 Billiard M, Besset A, Cadilhac J. The clinical and polygraphic development of narcolepsy. In: Guilleminault C, Lugaresi E, eds. Sleep-wake disorders: natural history, epidemiology and lon term evolution. New York: Raven Press, 1983:171-85.

5 Rechtschaffen A, Wolpert EA, Dement WC, Mitchell SA, Fisher C. Nocturnal sleep of narcoleptics. Electroencephalogr Clin Neurophysiol 1963;15:599-609.

6 Mosko SS, Shampain DS, Sassin JF. Nocturnal REM latency and sleep disturbance in narcolepsy. Sleep 1984;7:115-25.

Sleep 1984;7:115-25.
Sakai K. Central mechanisms of paradoxical sleep. In: Borbély A, Valatz JL, eds. Sleep mechanisms. Berlin: Springer-Verlag, 1984:3-18.

8 Erlich SS, Itabashi HH. Narcolepsy: a neuropathological study. Paper presented at 2nd international symposium on narcolepsy, Stanford, Ca, 1985. Sleep (in press).

9 Honda Y, Dol Y, Juji T, Satake M. Narcolepsy and HLA. Positive DR2 as a prerequisite for the development of narcolepsy. In: Proc 6 fap Soc Biol Psychiat, Tokyo, March 23-24, 1984. p6.

10 Billiard M, Seignalet J. Extraordinary association between HLA-DR2 and narcolepsy. Lance 1985;i:226-7.

11 Langdon N, Welsh K, van Dam M, Vaughan RM, Parkes JD. Genetic markers in narcolepsy. Lancet 1984;ii:1178-80.

12 Srikanta S, Ganda OmP, Rabizadeh A, Soeldner JS, Eisenbarth GS. First-degree relatives of patients with type 1 diabetes mellitus: islet cell antibodies and abnormal insulin secretion. N Engl f Med 1985;313:461-4.

13 Gorsuch AN, Spencer KM, Lister J, et al. Evidence for a long prediabetic period in type 1 (insulin-dependent) diabetes mellitus. Lancet 1981;ii:1363-5.

14 Foutz AS, Mitler MM, Cavalli-Sforza LL, Dement WC. Genetic factors in canine narcolepsy. Sleep 1979;1:413-21.

\section{Recognising whooping cough}

Now that the sight and sounds of a whooping cough paroxysm are broadcast to the nation through repeated television advertising there might seem little excuse for a doctor who fails to diagnose this unpleasant disease. In fact, missed or late diagnosis is commonplace.

A review of hospital case notes in the United States showed that during an eight year period admitting house officers initially considered pertussis in only 24 of 61 children later found to have the disease. ${ }^{1}$ Inexperience may have been the explanation, but British general practitioners, too, show wide variation in their willingness to make the diagnosis - at least in adults. ${ }^{2}$ Part of the explanation is that mild infection may present with minimal symptoms. Recognition in the initial catarrhal stage is likely only if practitioners are alert to a history of contact.

In children the disease differs clinically in various ways, from bronchiolitis, acute bronchitis, and pneumonia. Children with whooping cough are very unlikely to have a temperature of over $38.4^{\circ} \mathrm{C}$, or to wheeze; but most vomit when they have the paroxysms. The cough itself is less spontaneous than in other chest infections: it is provoked by feeding and other exertion and is frequently worse at night. ${ }^{134}$ The last two features may cause confusion in infants with that type of asthma which presents with cough rather than wheeze, but malaise and vomiting are unusual in asthma. Chronic asthmatics reasonably well controlled with prophylactic medication may report an increased tendency to cough as the only symptom of pertussis. Rather than automatically increase antiasthmatic treatment the clinician would do well to join his patient on a brief run. The cough provoked has a different quality from that of exercise asthma: adult patients with chronic obstructive airways disease who acquire pertussis can themselves describe the unusual nature of the cough. In general, adults suffer similar symptoms to children except a whoop is most rare and persistent sore throat is a frequent additional complaint. ${ }^{2}$

The laboratory has something to offer: microbiological confirmation is specific but insensitive. The usual methods of collection and transport of specimens from the surgery to hospital are too complex and lengthy for this fastidious organism. Direct fluorescent antibody testing on nasopharyngeal aspirates gives a rapid answer which is reliable if positive, but false negative results are common. ${ }^{5}$ Immunoelectrophoresis looks promising, and early experience suggests that its sensitivity is better than that of microbiological culture. ${ }^{6}$ These newer techniques give a result the same day and they will be valuable as they become more widely available.

Making a correct diagnosis is always intellectually satisfying but in the case of pertussis how much does it matter? American interns who diagnose Reye's syndrome instead of pertussis may well overtreat their patients, while in Britain 